\title{
Alexandre Papas, Soufisme et politique entre Chine, Tibet et Turkestan. Étude sur les KhwajasNaqshbandis du Turkestan oriental
}

Préf. de Marc Gaborieau. Paris, Jean Maisonneuve, coll. " Monde caucasien et tatar - Asie centrale

et Haute Asie », 2005, 291 p.

Élisabeth Allès

\section{(2) OpenEdition}

Journals

Édition électronique

URL : http://journals.openedition.org/assr/4010

DOI : $10.4000 /$ assr.4010

ISSN : $1777-5825$

Éditeur

Éditions de l'EHESS

Édition imprimée

Date de publication : 1 décembre 2006

Pagination : 115-283

ISBN : 2-7132-2124-2

ISSN : 0335-5985

Référence électronique

Élisabeth Allès, «Alexandre Papas, Soufisme et politique entre Chine, Tibet et Turkestan. Étude sur les KhwajasNaqshbandis du Turkestan oriental », Archives de sciences sociales des religions [En ligne], 136 | octobre - décembre 2006, document 136-82, mis en ligne le 14 février 2007, consulté le 21 septembre 2020. URL : http://journals.openedition.org/assr/4010 ; DOI : https://doi.org/10.4000/assr.4010

Ce document a été généré automatiquement le 21 septembre 2020.

(C) Archives de sciences sociales des religions 


\section{Alexandre Papas, Soufisme et politique entre Chine, Tibet et Turkestan. Étude sur les KhwajasNaqshbandis du Turkestan oriental}

Préf. de Marc Gaborieau. Paris, Jean Maisonneuve, coll. « Monde caucasien et tatar - Asie centrale et Haute Asie », 2005, 291 p.

Élisabeth Allès

1 Parmi les nombreuses publications en langues occidentales dont fait l'objet le Xinjiang depuis ces dernières années, il manquait une approche historique qui prenne comme point de départ l'optique de l'intérieur du monde turkestanais. C'est ce que fait Alexandre Papas avec l'histoire des Khwâjagan de la confrérie naqshbandie et de la fondation d'une théocratie islamique par l'une de ses branches dans l'Altishahr (sud du Xinjiang actuel) entre la fin $\mathrm{du} \mathrm{XVI}^{\mathrm{e}}$ siècle et le milieu du XvIII ${ }^{\mathrm{e}}$ siècle.

2 Une telle démarche, qui nécessite l'usage de plusieurs langues de la région, avait été initiée par le remarquable historien américain, J. Fletcher, décédé en 1984, qui étudiait les textes en persan, turk chaghatay, russe, arabe, chinois et japonais. A. Papas utilise les quatre premières de ces langues, s'appuie sur un corpus composé de chroniques historiques et «renoue " avec l'étude des hagiographies soufies. Cette démarche de l'intérieur pousse l'auteur à remettre en cause une hypothèse de J. Fletcher qui considérait le développement de la Naqshbandiyya en Asie centrale et jusqu'en Chine comme la manifestation d'un vaste mouvement de renouveau confrérique au XvIII siècle. Pour sa part, A. Papas relève toute l'importance de l'histoire locale de l'Asie centrale dans le développement des confréries pour cette période.

3 L'ouvrage est divisé en quatre parties. Les deux premières et la dernière traitent de la fondation et de la montée en puissance de la confrérie étudiée ainsi que de sa chute 
jusqu'à la conquête Qing (1755-1759). Makhdûm-i A'zam de Samarkand est le fondateur de cette branche "singulière » en raison de l'instauration du principe héréditaire qui conduit la confrérie dans un processus de formation dynastique sous le nom de Makhdûmzâda. L'auteur relève, comme J. Fletcher, le caractère fortement missionnaire de cette confrérie qui se développe dans le bassin du Tarim. L'extension de l'islamisation s'inscrit dans un contexte particulier: déclin de l'activité d'une autre confrérie soufie, l'Uwaysiyya, et prégnance de références religieuses multiples parmi lesquelles dominent chamanisme et bouddhisme lamaïste. Par ailleurs l'enseignement de Makhdûm-i A'zam comporte une préoccupation: la présence des shaykhs tant auprès des gouvernants qu'au sein de la population. Mais, comme souvent en islam, c'est la question de la succession qui va provoquer une profonde et violente rupture et qui donnera naissance à deux branches, Ishâqiyya et Âfâqiyya. La première défend le maintien d'une chaîne initiatique non héréditaire liée au rôle prépondérant du khalîfa (missionnaire, vicaire) et la seconde soutient, pour sa part, le caractère absolu de la règle d'hérédité renforcée par la règle d'aînesse ou selon les termes de l'auteur, le majorat (p. 73).

Envoyé par son père, Ishâq Khwâja parvient à Kashgar en 1580. De nombreux miracles lui sont attribués et le rendent populaire dans les oasis du Tarim. Il devient le maître spirituel de Kashgar malgré les fortes réticences des oulémas locaux. En 1591-92, la Naqshbandiyya ishâqiyya devient la confrérie " officielle » du khanat Sa îdiyya. L'îshan demeure toutefois dans une relation de subordination au khan. Ishâq Khwâja organise la confrérie en promouvant le rôle du khalîfa qui a pour fonction de diffuser la doctrine et d'appliquer la sharĩa.

5 Du point de vue de la doctrine, les deux confréries ne diffèrent guère, et suivent toutes deux l'enseignement du fondateur qui, outre le Coran et les hadiths, s'appuie sur le Mathnawî-yi ma'nawî de Jalâl al-Dîn Rûmî. L'accent est mis sur le culte des saints autour des mazâr (mausolées) qui deviennent des centres de dévotion et de pratiques mystiques, sur l'organisation de la sociabilité avec les kânaqâh (couvents) et sur le souci de la perpétuation du lignage. On remarque au passage quelques influences locales, peut-être bouddhistes, dans l'usage des étendards. L'auteur, en outre, précise qu'en raison même de la tolérance par Makhdûm-i A'zam des deux formes de dhikr, silencieux et vocal, cette différence ne joue pas dans le conflit violent entre les deux branches soufies alors qu'elle aura un rôle non négligeable dans la rivalité entre deux autres confréries naqshbandies en Chine même.

6 À la mort du fondateur de la confrérie, la branche du fils aîné doit se réfugier, en 1622, à Qomul et en 1653 le dernier souverain Saî̀di protecteur des Ishâqi, expulse la Kashgarie Âfâq Khwâja (issu de la branche aînée). Commence alors un exil de dix ans, raconté sur le modèle de l'exil du Prophète, qui conduira Âfâq Khwâja au Kashmir, au Tibet, à Lhassa, puis dans l'Amdo et jusqu'au Gansu. Ainsi se forme la confrérie Naqshbandiyya âfâqiyya qui aura des ramifications en islam chinois par la fondation d'une branche de la Naqshbandiyya, la Khufiyya. L'expérience de l'exil permet d'affirmer la sainteté du shaykh. La spiritualité du saint soufi s'affirme à travers divers miracles et le récit de rencontres prestigieuses - impossible à vérifier selon l'auteur avec le cinquième Dalaï Lama et de la guérison imaginaire de l'empereur de Chine. Toutefois le passage au Tibet lui apporte le soutien des Mongols Jungghars (bouddhistes lamaïstes) qui dominent la région à la fin $\mathrm{du} \mathrm{xVII}^{\mathrm{e}}$ siècle et qui permettent à Âfâq Khwâja d'accéder au pouvoir sur l'Altishahr, tout en restant sous leur tutelle et contre 
le versement d'un tribut. Les conflits violents pour la prééminence entre les deux branches de la confrérie, les revirements politiques et militaires des khan et autres personnages permettront de fait, après le massacre des Junggars à Ghuljâ (Ili), la conquête rapide de la région qui sera nommée Xinjiang (nouvelle frontière) par l'empire des Qing.

7 Le troisième chapitre est sans doute le plus original, il est consacré au rapport du religieux et du politique et à ce que souligne Marc Gaborieau dans la préface, un exemple de "sacralisation du pouvoir ». L'auteur s'appuie sur un texte hagiographique en persan encore peu étudié, le Hidâyat nâma de Mîr Khâl al-Dîn al-Yârkandî et en extrait les principes d'une institution théologico-politique qu'il appelle «Ishanat », qui n'aura cependant que quelques années d'existence. Pour Âfâq Khwâja, il faut "subordonner toute souveraineté au saint Ishân dont le pouvoir s'étendrait à tous les domaines de la vie de la communauté ». Pour cela, il va prendre des moyens que l'on pourrait considérer comme modernes sur le plan à la fois fiscal et administratif mais surtout social en étendant le modèle de la confrérie soufie à l'ensemble de la société. La vie religieuse et mystique s'accomplit au cœur de la cité et en public et non plus en marge. Le shaykh institutionnalise trois degrés d'allégeance (bay'at), les affiliés, les initiés et les héritiers qui permettent d'intégrer l'ensemble de la population dans le système, sans obligation pour les membres de la première catégorie d'être des soufis très assidus mais en échange d'une " fidélité absolue au shaykh ».

L'ouvrage de A. Papas est une contribution à l'histoire turkestanaise qui vient compléter par son analyse de l'ishanat les travaux déjà effectués. Or l'auteur ne signale pas, dans sa bibliographie, l'ouvrage de référence en Chine sur l'histoire des Khwâja, publié en 1998. Il s'agit de recherches conduites par de remarquables historiens chinois spécialisés sur cette région depuis plus de quinze ans, Liu Zhengyin et Wei Liangtao (Xiyu hezhuo jiazu yanjiu [Les Khwâjas de la région de l'ouest], Beijing, Zhongguo shehuikexue chubanshe). Ils utilisent les mêmes sources en persan, en turc chagatai, en russe qu'A. Papas, ainsi que les études japonaises et bien sûr les sources chinoises, très utiles pour comprendre les rapports de forces régionaux. Ces travaux portent principalement sur l'histoire politique mais ont le même souci de comprendre l'histoire musulmane et soufie de la région. 